\title{
Ambient Noise and Teleseismic Signals Recorded by Ocean-Bottom Seismometers Offshore Eastern Taiwan
}

\author{
Ching-Ren Lin ${ }^{1,2}$, Ban-Yuan Kuo ${ }^{1,2, *}$, Wen-Tzong Liang ${ }^{1}$, Wu-Cheng Chi ${ }^{1}$, \\ Yu-Chih Huang ${ }^{2}$, John Collins ${ }^{3}$, and Chien-Ying Wang ${ }^{2}$ \\ ${ }^{1}$ Institute of Earth Sciences, Academia Sinica, Taipei, Taiwan \\ ${ }^{2}$ Department of Earth Sciences, National Central University, Jhongli, Taiwan \\ ${ }^{3}$ Department of Geology and Geophysics, Woods Hole Oceanographic Institution, Woods Hole, Massachusetts, USA
}

Received 14 March 2009, accepted 14 September 2009

\begin{abstract}
Broadband records from ocean-bottom seismometers deployed in the Okinawa trough and the Huatung basin were analyzed to provide seafloor noise characteristics and the detection thresholds for teleseismic body and surface waves. Ambient noise levels on the horizontal components are $10-40 \mathrm{~dB}$ higher than on the vertical component, with the sensor seated on the surface of the sediment. On the vertical components, infragravity waves are $10-30 \mathrm{~dB}$ more energetic at the shallower Okinawa trough sites ( $\leq 2000 \mathrm{~m}$ depth) than at the deeper Huatung basin site $(\sim 4700 \mathrm{~m})$. From 0.03 to $0.2 \mathrm{~Hz}$, the Huatung basin noise levels are comparable to that of the broadband stations in Taiwan on a quiet day. The microseism peaks $(\sim 0.2-$ $0.5 \mathrm{~Hz}$ ) of OBSs reach or exceed the high noise model of continental stations. At regional distances $\mathrm{M}_{\mathrm{w}} 6.5$ is required for recording prominent Rayleigh waves if the source radiation is unfavorable, but 6.2 is sufficient for a favorable focal mechanism. Several tens to over one hundred high-fidelity $P, P_{\text {diff }}$ and $P K P$ waveforms have been recorded per year by OBSs at high corner frequency of $0.1 \mathrm{~Hz}$ with a minimum $\mathrm{M}_{\mathrm{w}} 5.3$ - 6.0. The number of recording drops to less than 5 per year at $1 \mathrm{~Hz}$ with $\mathbf{M}_{w} \geq 6.4$ and distances less than $90^{\circ}$.
\end{abstract}

Key words: OBS, Noise level, Detection threshold

Citation: Lin, C. R., B. Y. Kuo, W. T. Liang, W. C. Chi, Y. C. Huang, J. Collins, and C. Y. Wang, 2010: Ambient noise and teleseismic signals recorded by ocean-bottom seismometers offshore eastern Taiwan. Terr. Atmos. Ocean. Sci., 21, 743-755, doi: 10.3319/TAO.2009.09.14.01(T)

\section{INTRODUCTION}

Understanding the noise spectrum on the sea bed is crucial to the design and installation of ocean-bottom observatories. In 2006, the Institute of Earth Sciences at Academia Sinica started the deployment of broadband ocean-bottom seismometers (OBSs) in the eastern waters of Taiwan. The system was built at the Woods Hole Oceanographic Institute (WHOI) ocean-bottom seismology laboratory, and similar broadband instruments have been employed in various campaigns to study the structure of the upper mantle (Collins et al. 2001, 2002, 2008). The broadband system we used is equipped with a Guralp CMG-3Tc sensor, which has a velocity response flat to $120 \mathrm{~s}$, a gimbal to level the sensor, a Quanterra Q330 datalogger, and a Seascan clock which maintains the time at a drift rate of less than $2 \mathrm{~s}$ a year. The

\footnotetext{
* Corresponding author

E-mail:byk@earth.sinica.edu.tw
}

sensor ball is separated from the main package and seated on the surface of the seafloor. By late 2008, waveform data 9 - 12 month long for each of the 3 OBSs were available for seismological research. Two OBSs were deployed concurrently during 2006 - 2007, with S002 in the Okinawa trough (OT) at the water depth of $1700 \mathrm{~m}$ and S004 in the Huatung basin at $4700 \mathrm{~m}$ (Fig. 1). S005 was deployed at $2000 \mathrm{~m}$ depth in the OT through 2007 - 2008.

In this study we present the ambient noise levels at these 3 sites and compare them with those at BATS (e.g., Liang et al. 2004, 2008; http://bats.earth.sinica.tw) stations installed near the coastline and in the center of the island and two F-net stations (Okada et al. 2004). Knowledge of ocean-bottom noise has accumulated from many OBS experiments at various sites throughout the world during the last two decades (e.g., Webb 1998, 2002; Collins et al. 2001). In this paper we do not intend a further interpretation 
of the mechanisms that cause the noise at different frequencies, but to present observations for the first time from this part of the globe. The reference stations from BATS all have a velocity response flat to at least $100 \mathrm{~s}$. HGSD is located $15 \mathrm{~km}$ inland from the east coast of Taiwan, with a sandfilled borehole sensor at a $100 \mathrm{~m}$ depth. TWKB is located $5 \mathrm{~km}$ from the coastline of the Hengchuan peninsula, and TDCB is installed at a quiet site in the middle of the Central Range of Taiwan (Fig. 1). YNG and IGK are F-net stations installed on the islands of Yonaguni and Ishigaki. The high and low noise model compiled by Peterson (1993) provides a global reference for continental sites.

\section{NOISE LEVELS}

Power-spectral density (PSD), in unit $10 \times \log _{10}$ $\left(\mathrm{m}^{2} \mathrm{~s}^{-4} \mathrm{~Hz}^{-1}\right)$ or $\mathrm{dB}$, was calculated from a three-hour interval exclusive of obvious seismic signals extracted from both OBS and land-station records on a relatively quiet day.
Figure 2 shows the general pattern in noise level for different stations. As explained below, the vertical component of OBSs characterizes the natural condition of the seafloor better than the horizontal components, so we will focus on the noise levels on the vertical component. The noise notch is registered between $0.02-0.05 \mathrm{~Hz}$ on the vertical components of OBSs (Fig. 2a), but broadens at lower frequencies on the land-stations. From the notch, noise levels increase on both sides. At the steep slope toward higher frequencies there exists the small-amplitude, single-frequency microseism. The large-amplitude microseisms peak at 0.2 $0.5 \mathrm{~Hz}$, and the noise decreases with increasing frequency before flattening or increasing again. In general, while the patterns of spectrum are similar on the ocean bottom and on the land, the ocean environment is noisier than the land for most of the frequencies.

To fully describe temporal variations, three forms of spectra are provided. Snapshots on selected quiet days for every other month are shown in Fig. 3. Probability den-

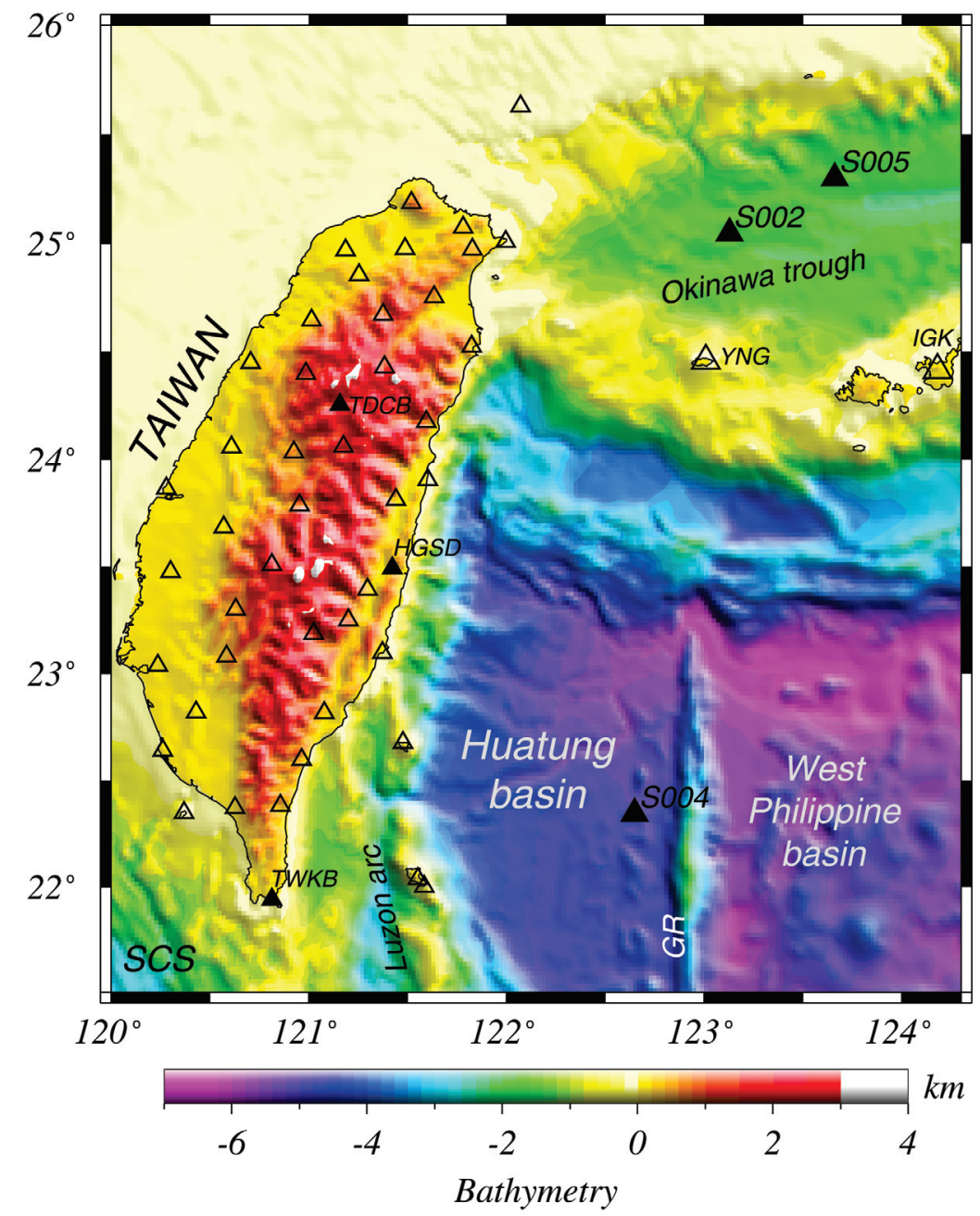

Fig. 1. Deployments of broadband OBSs S002, S004, and S005 (large, filled triangles) in the Huatung basin and the Okinawa trough, offshore eastern Taiwan. The reference stations are TDCB, TWKB, and HGSD (filled triangles) of BATS (open triangles) and the two F-net stations in the region, YNG and IGK. Tectonic elements are labeled. GR: Gagua ridge; SCS: South China sea. 

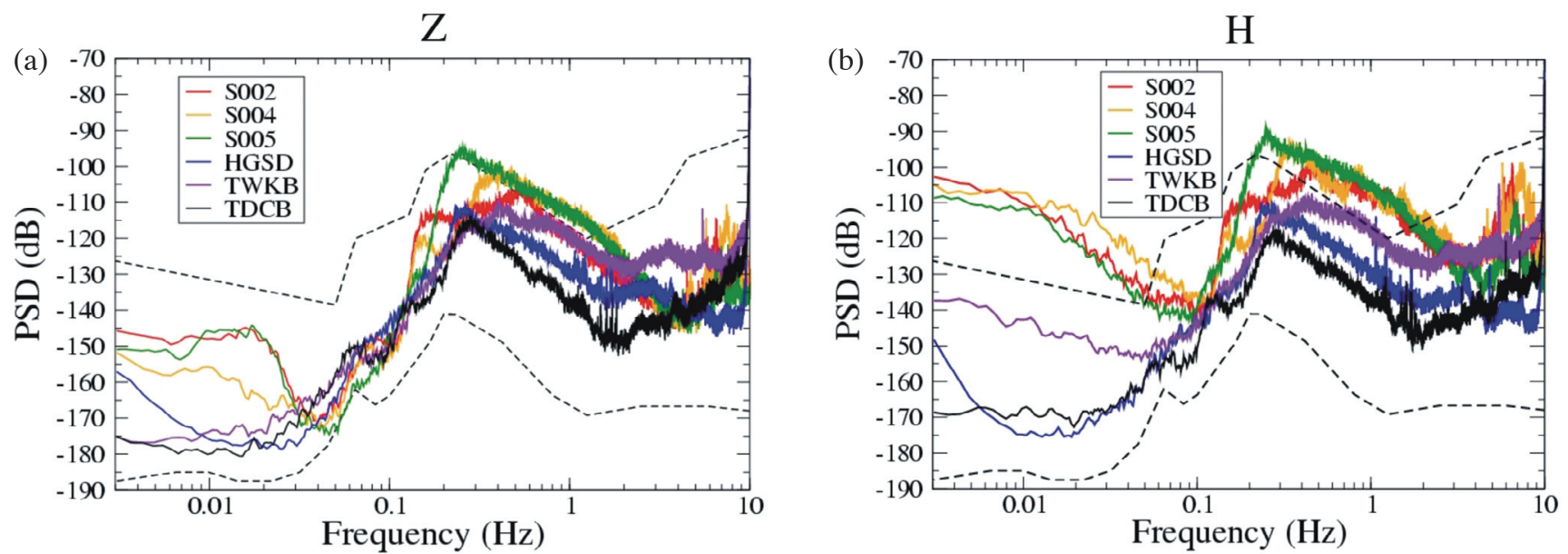

Fig. 2. Power spectral density of vertical (a) and horizontal (b) components of OBSs, compared with that of HGSD, TDCB, and TWKB of BATS, on a quiet day. The high and low continental noise model by Peterson (1993) is shown as a reference (dotted lines).
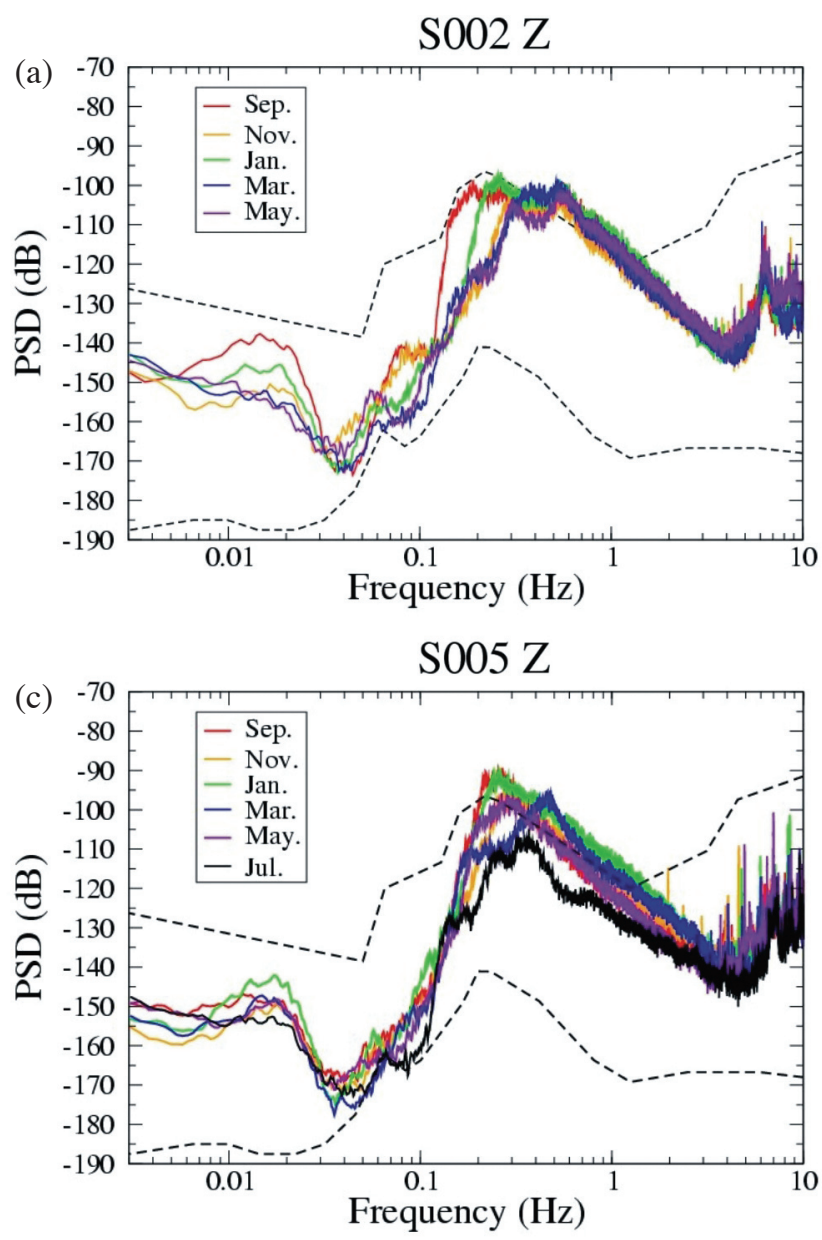

sity functions (PDF) were calculated using the method of MaNamara and Buland (2004) for every season and are displayed in Fig. 4. The mode of the PDFs is chosen to illustrate the most likely scenario for each season. In Fig. 5, daily mode data are plotted against date to form spectro-

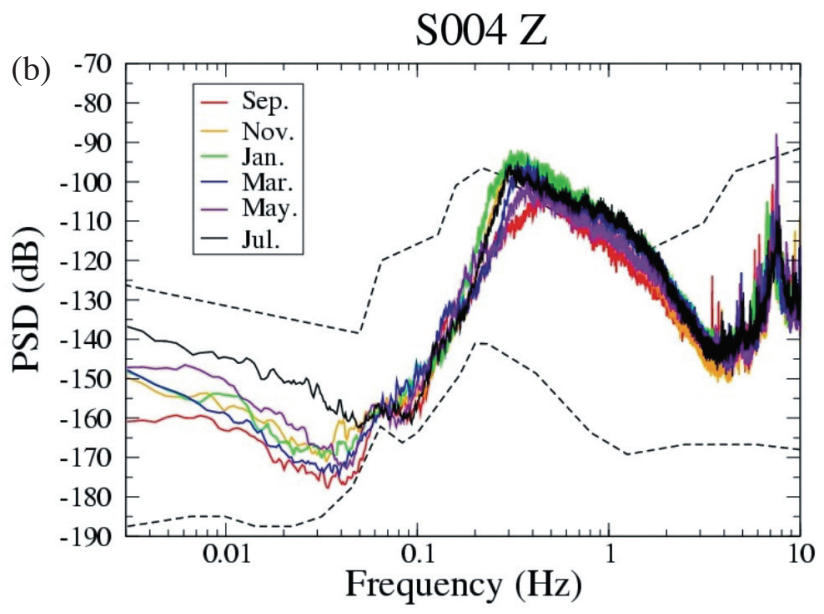

Fig. 3. Vertical-component PSD of three hour data of every other month to display snapshots of temporal variations. (a) S002, (b) S004, and (c) S005. grams. The seasonal variations are within $10 \mathrm{~dB}$ for most of the frequencies at S002 and S005 (Fig. 4). However, S004 exhibits different patterns in that there is a notable up shift in noise level at frequencies less than $\sim 0.03 \mathrm{~Hz}$ from early 2007 until the end of the experiment (Figs. 4 and 5). The 

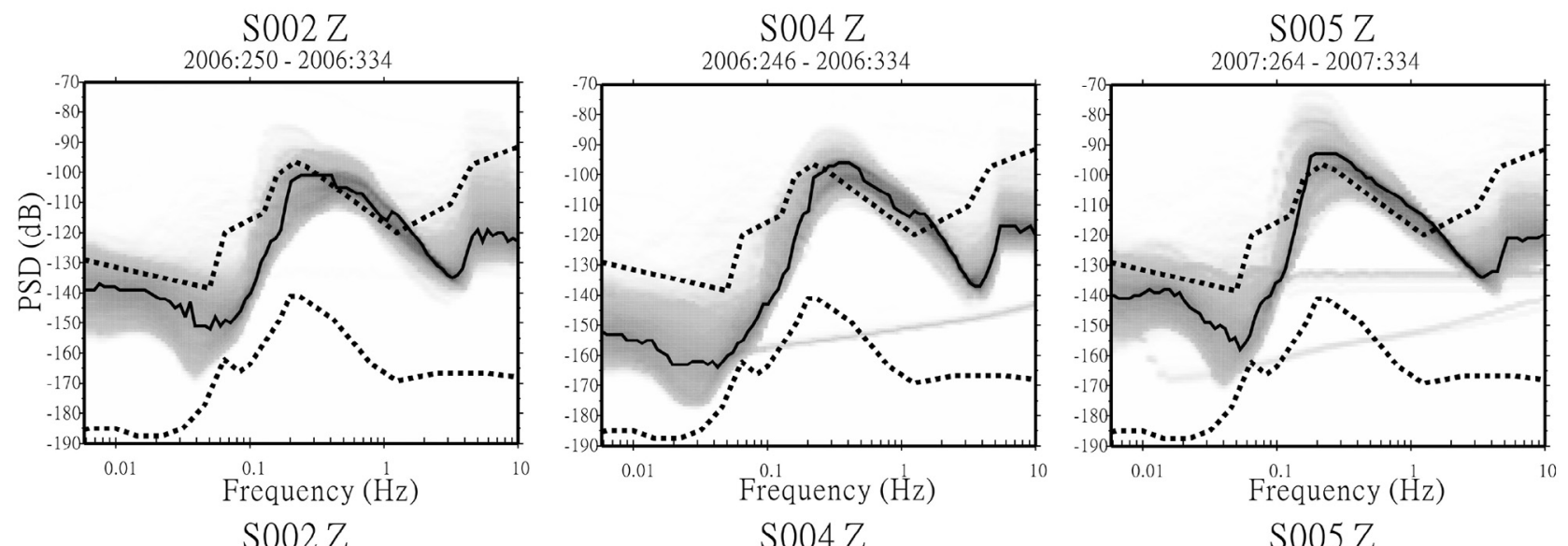

S002Z
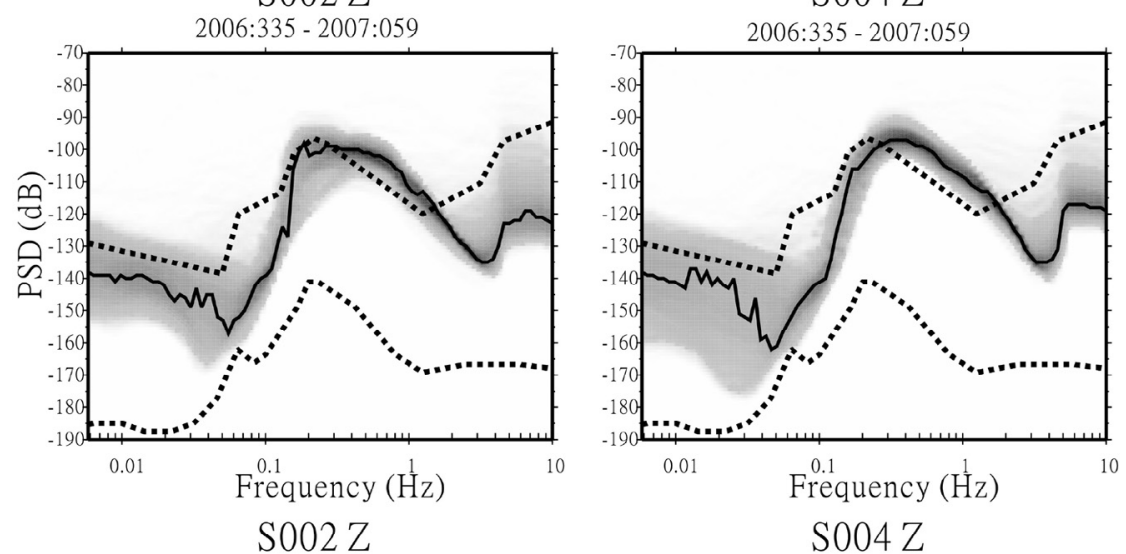

S005 Z

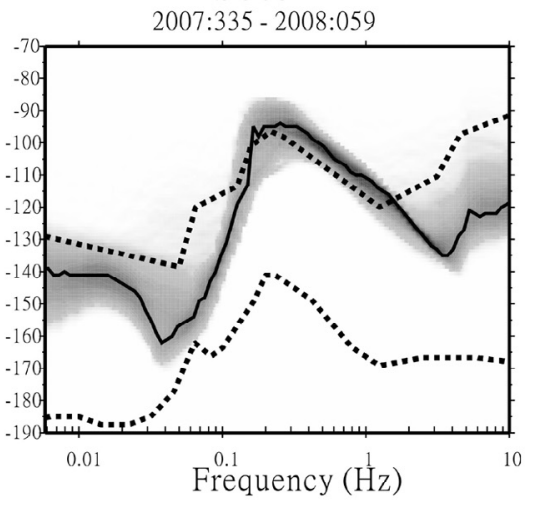

S004 Z
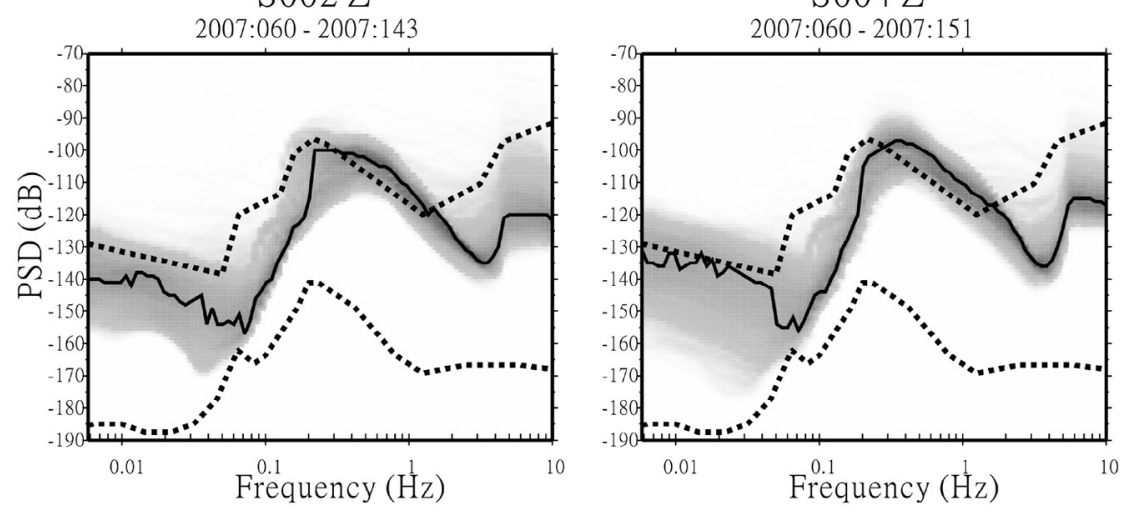

S005 Z

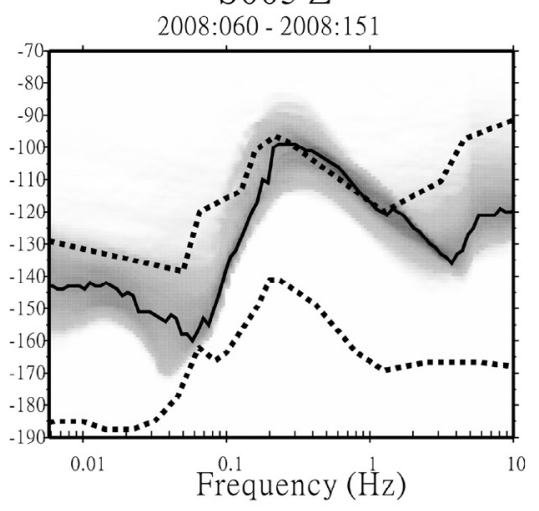

S004 Z
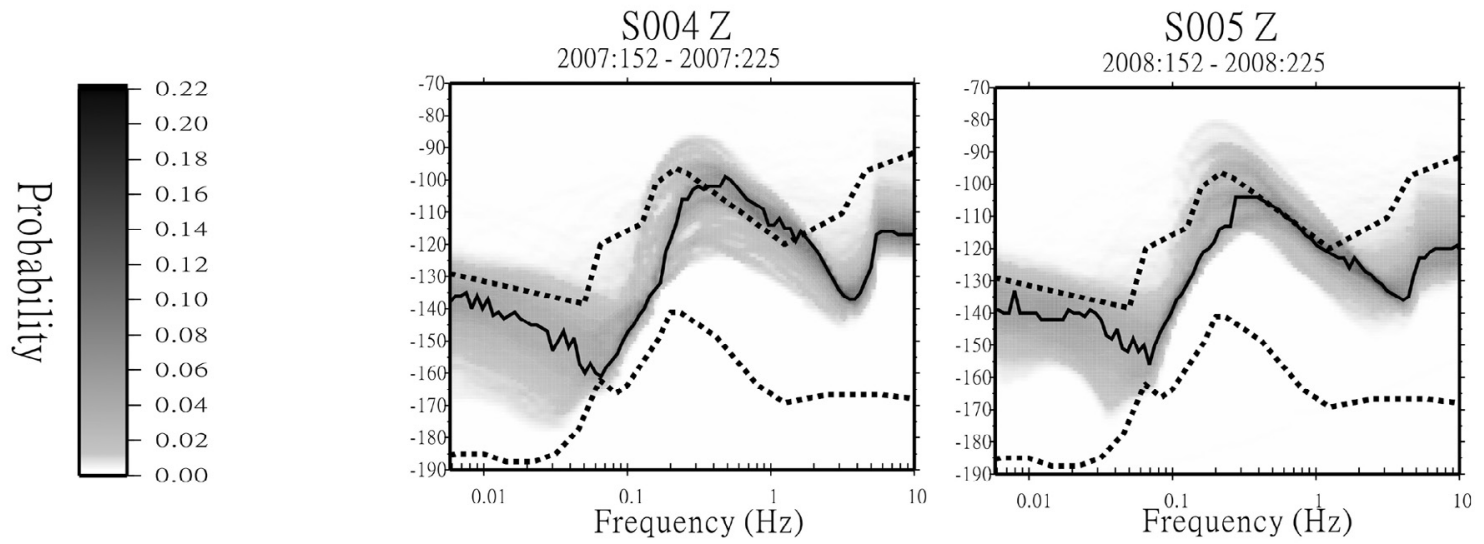

Fig. 4. PDFs (gray scaled) for the four seasons, for S002 (left), S004 (middle), and S005 (right column). From top to bottom rows: autumn (September - November), winter (December - February), spring (March - May), and summer (June - August) (S002 does not have 2007 summer data). The modes of the seasonal samples (solid line) show a weak variation of within $10 \mathrm{~dB}$ at most frequencies. The low-frequency noise level change at S004 is pronounced (see text). The mod data capture the infragravity wave humps better at S005 than at S002. 

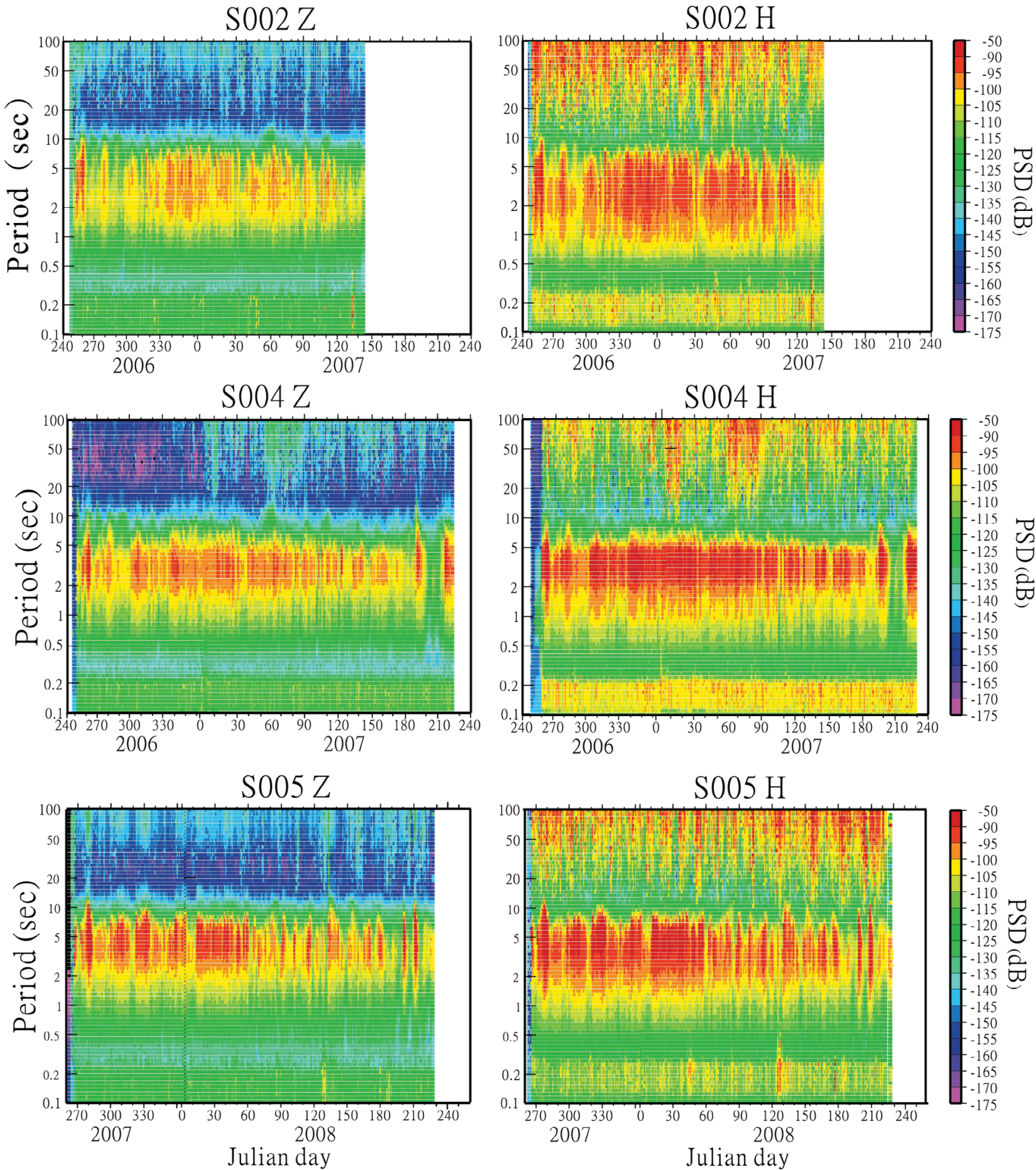

Fig. 5. Spectrograms of S002, S004, and S005 (from top to bottom) constructed by the mode of the PDFs each day. Note the vertical axis is period. Left: vertical component. Right: horizontal component. Each diagram is labeled by station and component names on the top. The spring-tide moderated amplitude variation of long-period noise level can be seen on both components, but more pronounced on the horizontal components at S002 and S005 due to the choice of color code. S004 shows the January and March 2007 spurs on both components at long periods.

increase relative to the calm 2006 is most dramatic in two intervals in spring 2007: the first half of January and from the end of February throughout March 2007. The origin of this month-long noise "spur" is uncertain, but this, together with the other forms of temporal variations, emphasizes that the three-hour spectra in Fig. 2 are not representative of the long term condition of the seafloor. Nonetheless, as in other reports (e.g., Collins et al. 2001; Dolenc et al. 2005), the quiet-day snapshot is provided to show end-member scenarios that can be compared with the reference data on land. 
A sensor that rests on the surface of the sediment is not well coupled to the ground and is subject to tilt by bottom currents which increase the low-frequency noise levels on the horizontal components much more significantly than on the vertical component (e.g., Collins et al. 2001). On a quiet day, the two components can differ by $40 \mathrm{~dB}$ at $0.01 \mathrm{~Hz}$. Emplacement of sensor in the sediment or in the borehole deep into the basaltic crust reduces the tilt noise effectively (Webb 1998; Collins et al. 2001; Shinohara et al. 2006; Duennebier and Sutton 2007). This practice, however, was not undertaken with the WHOI OBSs in recent experiments in the vicinity of Taiwan and in Hawaiian waters (Collins et al. 2008). The following discussion is focused on the performance of the vertical component in Figs. 2 - 5 except for the purpose of comparison. The spectrum is divided into three frequency bands for convenience.

\subsection{Frequencies $0.003-0.03 \mathrm{~Hz}$}

The ocean surface gravity waves excited by the tidal force and remote storms generate noise at low frequencies (e.g., Webb 1998). A recognizable repeating feature at long periods, illustrated better on horizontal components than on vertical component, is the fluctuation of the long-period noise amplitude twice a month (Fig. 5), which is apparently associated with the spring tides that occur when the Earth, Moon, and Sun are aligned approximately every half month. The spring tide effect at S004 is not as clear, probably being disturbed by the month-long noise spur in 2007 described above.

Overall, the OBSs see noise levels 20 - $30 \mathrm{~dB}$ higher than the BATS stations for periods greater than $30 \mathrm{~s} \mathrm{(Fig.} \mathrm{2).}$ The infragravity wave dominates the noise at $0.01-0.03 \mathrm{~Hz}$ as evident from the two OT sites. The "infragravity wave" refers to the long-period ocean waves that have been observed to peak between $0.01-0.02 \mathrm{~Hz}$, which are the frequencies lower than the wind-driven ocean waves and swell (Webb et al. 1991; Webb and Crawford 1999; Araki et al. 2004; Dolenc et al. 2005, 2008). Because the amplitude of the infragravity-wave decays exponentially with depth (Webb et al. 1991), the $10-20 \mathrm{~dB}$ "hump" relative to the background level seen at S002 (1700 m) and S005 (2000 m) vanishes at S004 (4700 m). The hump can diminish some times at S002 (Fig. 3), and the PDF distribution shows that it persists better at S005 (Fig. 4). The humps reach 10 $40 \mathrm{~dB}$ at sites 1000 - $3000 \mathrm{~m}$ depths offshore western North America and Japan (Araki et al. 2004; Dolenc et al. 2005, 2008). The Huatung basin appears to be shielded from infragravity waves, making it an ideal site for long-period surface wave observations with OBS. The high-quality Rayleigh waves recorded by S004 in the $0.025-0.04 \mathrm{~Hz}$ band have been employed as a unique tool to map the upper mantle of this part of the Philippine Sea plate (Kuo et al. 2009).

\subsection{Frequencies $0.03-0.3 \mathrm{~Hz}$}

This band covers part of the large-amplitude microseisms $(\sim 0.2-0.5 \mathrm{~Hz})$ and is the band in which the OBS can possibly rival the land receivers during quiescence. All the OBS noise levels rise from the noise notch near the continental low noise level to the continental high noise level (Peterson 1993) at $0.3 \mathrm{~Hz}$ (Figs. 2, 3, and 4). During most of 2006, S004 can be even quieter than the coastline station HGSD by $10 \mathrm{~dB}$ for frequencies $0.05-0.2 \mathrm{~Hz}$, although the latter is obviously quieter at lower frequencies. S004 is also comparable to TWKB and TDCB. This is the band in which the seafloor seismometer can perform equally well as buried instrumentation (e.g., Collins et al. 2001; Stephen et al. 2003; Shinohara et al. 2006). The primary, single-frequency microseism at $\sim 0.06 \mathrm{~Hz}$ can be seen at all sites despite with different shapes (Figs. 2 and 3), while it does not present itself evidently in the mode of the PDFs (Fig. 4), probably because it is a sharp and transient peak that is not pinned on exactly the same frequency for a long time. The secondary, large-amplitude microseisms are broad at $0.2-0.5 \mathrm{~Hz}$ and may or may not display the typical double peaks. At S005, the large-amplitude microseisms seem to peak at lower frequencies than at S004 for most of the time (Fig. 4).

\subsection{Frequencies $0.3 \mathrm{~Hz}$ and Higher}

This range includes the high-frequency part of the energetic microseisms driven by local winds. Higher frequency noises may be related to local sources such as microearthquakes, shipping, and shear modes in the low-rigidity sediments. On the quiet day selected for both S002 and $\mathrm{S} 004$, the former is quieter than the latter in this band. In comparison with the PDFs (Fig. 4), this difference is subtle and at present we do not have other independent data, such as wave heights or wind speed, to elaborate upon this possibility. The noise levels of all OBSs approach or surpass Peterson's (1993) continental high noise model. This indicates that even during a quiet day in the ocean bottom, noise levels are as high as at the most noisy continental site at high frequencies. This is expected as the OBS is closer to the ocean sources of the high frequency noise, which do not propagate far into the continent (e.g., Stephen et al. 2003). As shown below, the number of $P$ wave arrivals recorded with high signal-to-noise ratio in this frequency band is dramatically reduced from that at lower frequencies.

\section{TELESEISMIC SIGNALS}

Global and regional seismological studies rely on clear recordings of teleseismic phases. Because the noise is more energetic in the ocean than on the land, larger earthquakes and more favorable source radiations are required for a high quality waveform recording. As global distribution of 
potential seismic sources eligible for detection by the networks in the vicinity of Taiwan is known and will remain unchanged for a long time, one year deployment has accumulated enough data and experience to support an expectation for what we can achieve from future OBS deployments in the region.

\subsection{Rayleigh Waves}

In this section we show some examples of how the magnitude and the radiation pattern of the source play critical roles in Rayleigh wave observation under the potential interference of the long period ambient noise in the ocean. For regional-scale tomography, the useful Rayleigh wave frequency range is $0.01-0.05 \mathrm{~Hz}$ in which infragravity waves prevail at shallower sites. Figure $6 a$ shows all the shallow, $\mathrm{M}_{\mathrm{w}}>5$ events in the Kuril trench region during the deployment of S002 and S004. The CMT solutions (available from the Global CMT Project at http://www.globalcmt.org) and the calculated radiation patterns indicate that the southwest emanating Rayleigh waves have much smaller amplitudes than along the perpendicular direction (NW-SE). For an $\mathrm{M}_{\mathrm{w}} 5.9\left(\mathrm{M}_{\mathrm{s}} 6.1\right)$ event, Rayleigh waves were properly recorded by YNG and TDCB, but are not immediately recognizable on the OBS records (Fig. 7). After bandpass filtering to $0.01-0.3 \mathrm{~Hz}$ where surface wave and infragravity wave can coexist, it appears that the S002 waveforms are overwhelmed by the infragravity waves. At S004, because of the great water depth $(4700 \mathrm{~m})$, infragravity waves were much subdued and the Rayleigh waves stand out as the primary seismic signal. An $\mathrm{M}_{\mathrm{w}} 6.5$ earthquake is probably required to generate enough Rayleigh wave energy at S002 at a similar distance from an unfavorable source radiation (Fig. 8).

Another ideal surface-wave source region for Taiwan is New Britain and the Solomon Islands where the convergent plate boundary zone harbors numerous shallow, intermediate to large events at distances of $40-50^{\circ}$. The OBSs received relatively few useable Rayleigh waves from the Solomon Islands during the experiment, and the radiation patterns calculated from CMT solutions corroborate this (Fig. 6b). Several New Britain events, however, exhibit favorable radiations in generating Rayleigh waves to the azimuths of Taiwan. An example is an $M_{w} 6.2\left(M_{s} 6.2\right)$ that generated Rayleigh waves large enough to suppress the possible infragravity wave in the $0.01-0.03 \mathrm{~Hz}$ band at S002 (Fig. 9). Note the epicentral distances for this event are even longer than those in the case of the Kuril trench.

\subsection{Teleseismic $P$ Phase}

Recording clear teleseismic $P$ and $S$ phases by OBSs is of the utmost concern for the next generation global seismic network and regional studies with expanded broadband observation aperture. While small local events can be detected at high frequencies, teleseismic $P$ phases were usually identifiable at $\leq 1 \mathrm{~Hz}$ by seafloor seismometers for events with $\mathrm{m}_{\mathrm{b}}>6.0$ (e.g., Blackman et al. 1995; Toomey et al. 1998). In this section, we analyze the threshold relationship between

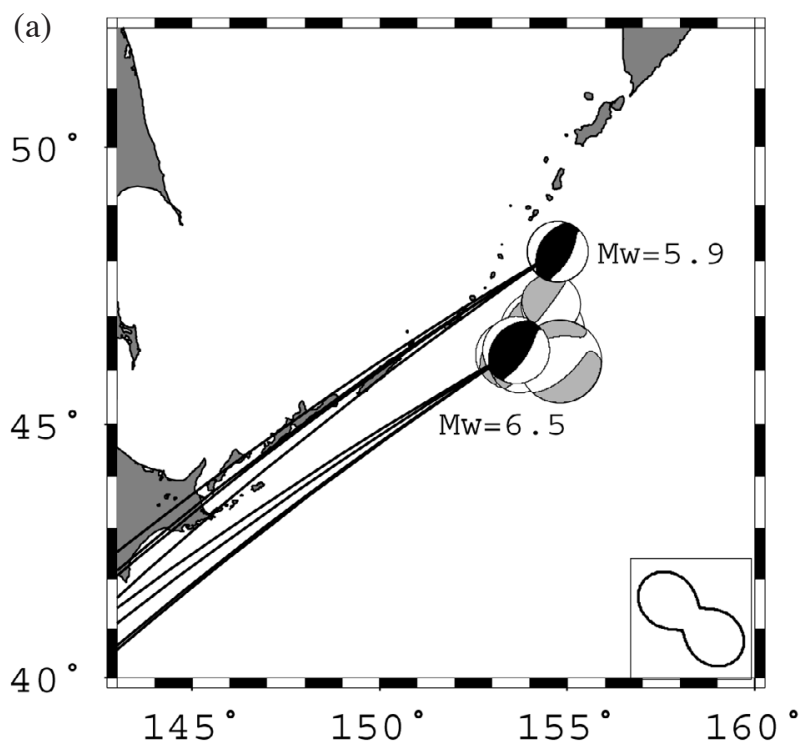

(b)

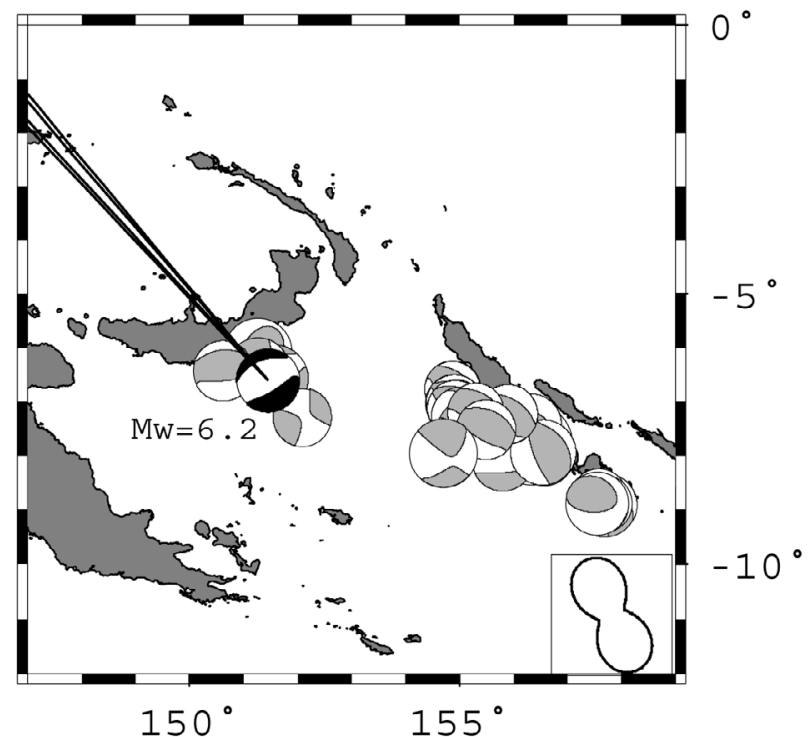

Fig. 6. The CMT solutions (gray tone)(The Global CMT Project at http://www.globalcmt.org) of the shallow events with $\mathrm{M}_{\mathrm{w}}>5.5$ in (a) the Kuril trench region and (b) the New Britain/Solomon Islands that provided Rayleigh waves recorded by stations in the Taiwan region during the one year deployment. Lines are great-circle paths from events to S002, S004, YNG (or IGK), and TDCB. The CMTs discussed in the text are dark filled and labeled with $\mathrm{M}_{\mathrm{w}}$. In (a), the two events are 2006.316.21.27 (year, Julian day, hour, minute), $\mathrm{M}_{\mathrm{w}}=5.9$ and 2006.274.09.06, $\mathrm{M}_{\mathrm{w}}=6.5$. The Rayleigh wave radiation pattern (inset at the lower right corner) exhibits weak radiations toward Taiwan (only from the larger event). In (b), the 2006.317.16.12, $\mathrm{M}_{\mathrm{w}}=6.2$ event has a favorable radiation to Taiwan. 
2006.316.21.27 Kuril $36 \mathrm{~km}$

$$
M w=5.9 M s=6.1
$$

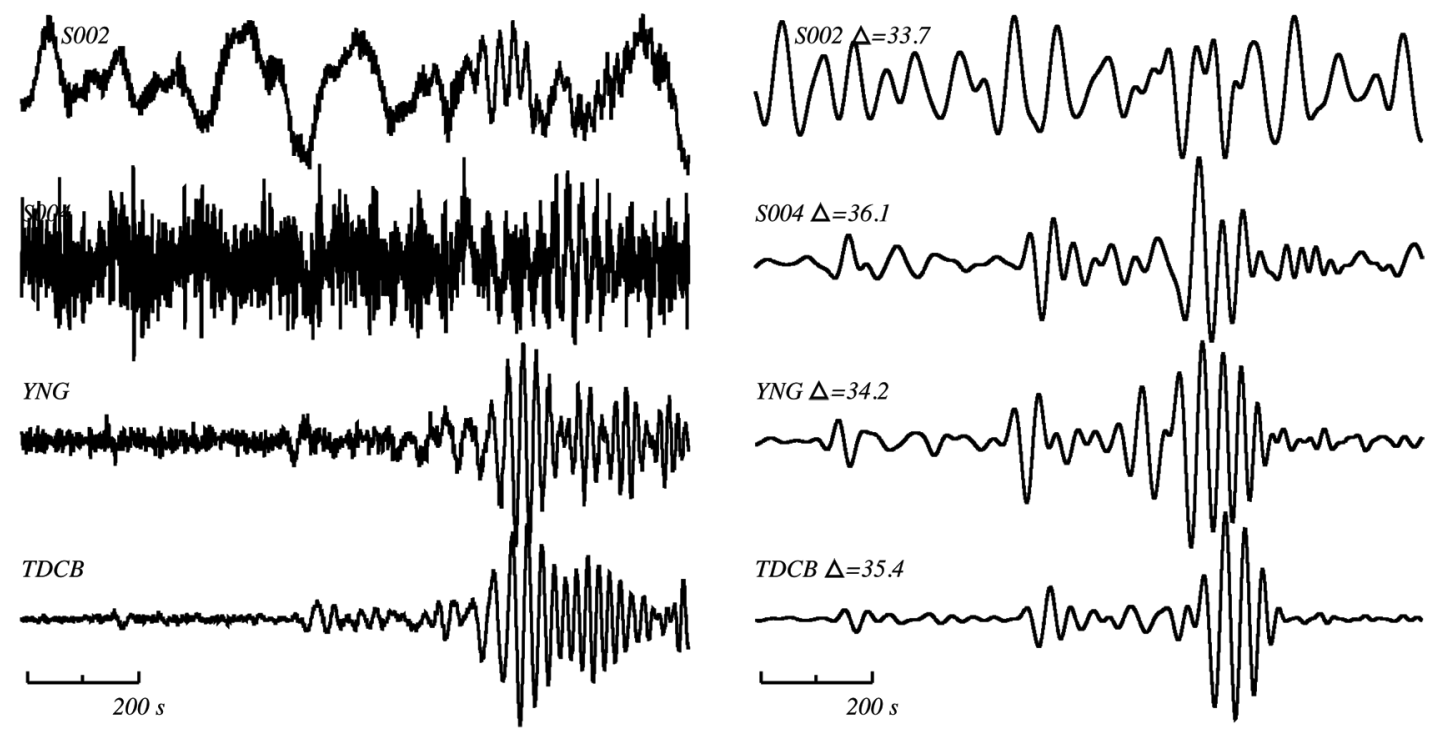

Fig. 7. Displacement waveforms at stations S002, S004, YNG, and TDCB for the smaller of the two events in Fig. 6a. Event depth, $\mathrm{M}_{w}$, and $\mathrm{M}_{\mathrm{s}}$ are shown on the top. Amplitudes are normalized. Left column: frequency $0.005-5 \mathrm{~Hz}$, showing nearly original waveforms. S002 is contaminated by both long-period and short-period noise, and S004 by short-period noise, compared with YNG and TDCB. Right column: $0.01-0.03$ Hz, showing the dominance of the infragravity wave at S002 because of its shallow seafloor site.

\subsubsection{Kuril $19 \mathrm{~km}$}

$$
M w=6.5 M s=6.6
$$
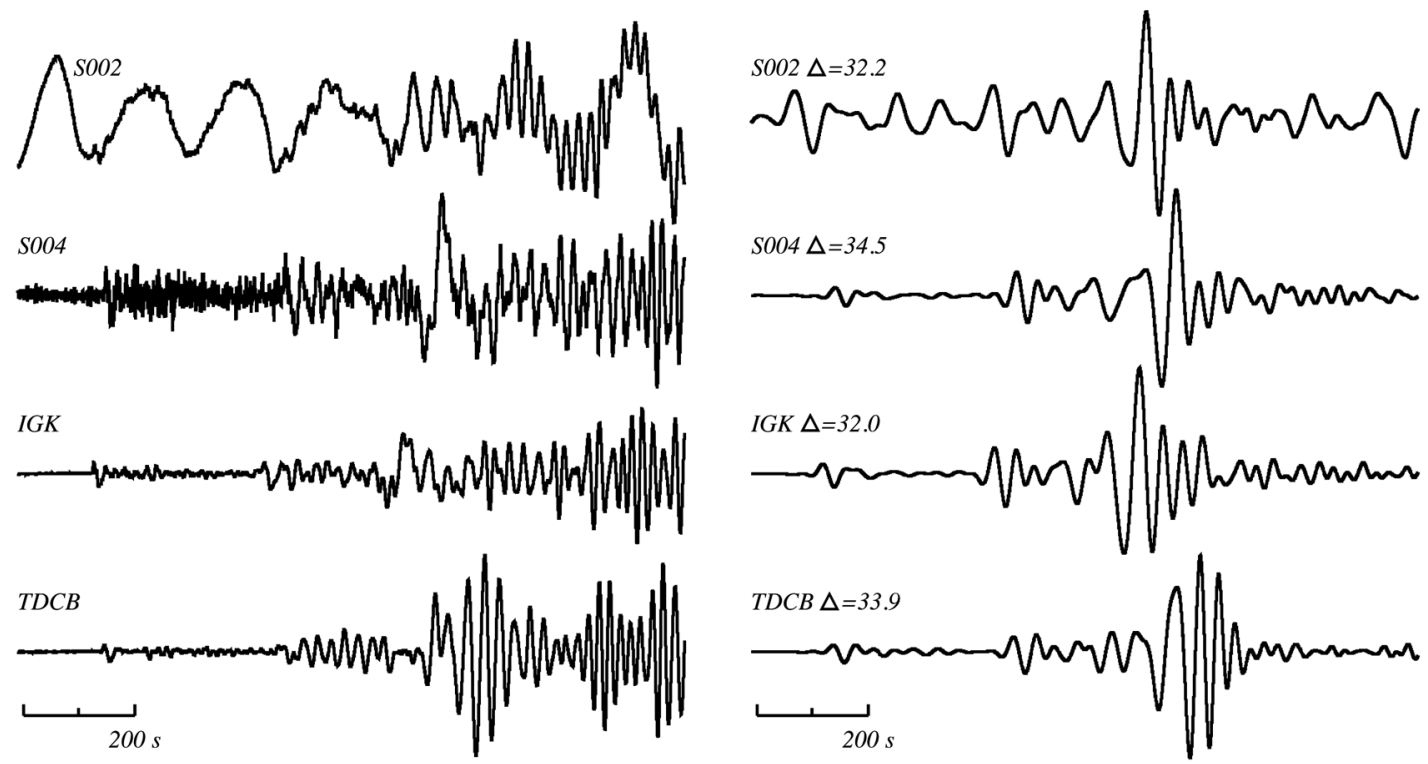

Fig. 8. The same as Fig. 7 except for the larger, $M_{w} 6.5$ event of the two in the Kuril region (Fig. 6a), showing dominant Rayleigh wave energy in the infragravity wave frequency band at all stations (right column). YNG is replaced by another F-net broadband station IGK. 


\subsubsection{New Britain $11 \mathrm{~km}$}

$$
M w=6.2 M s=6.2
$$

$0.005-5 \mathrm{~Hz}$

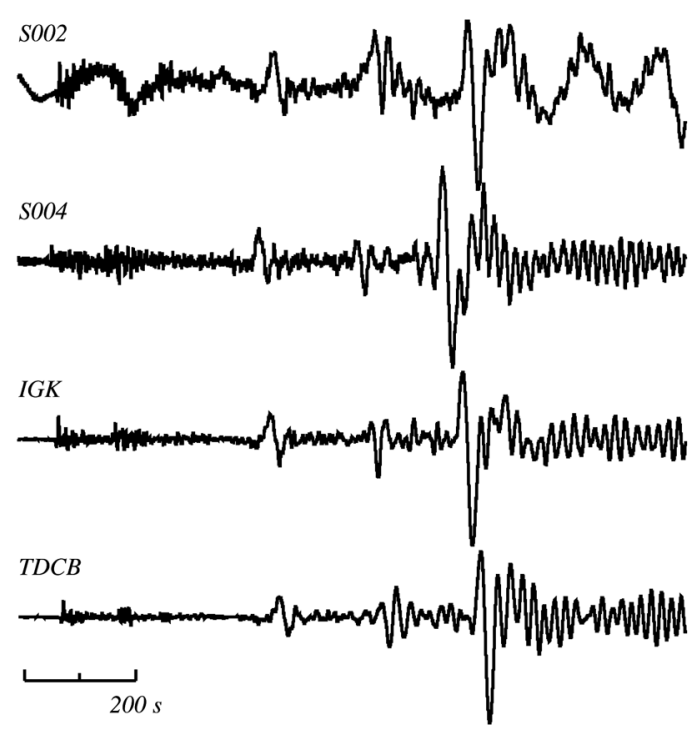

$0.01-0.03 \mathrm{~Hz}$

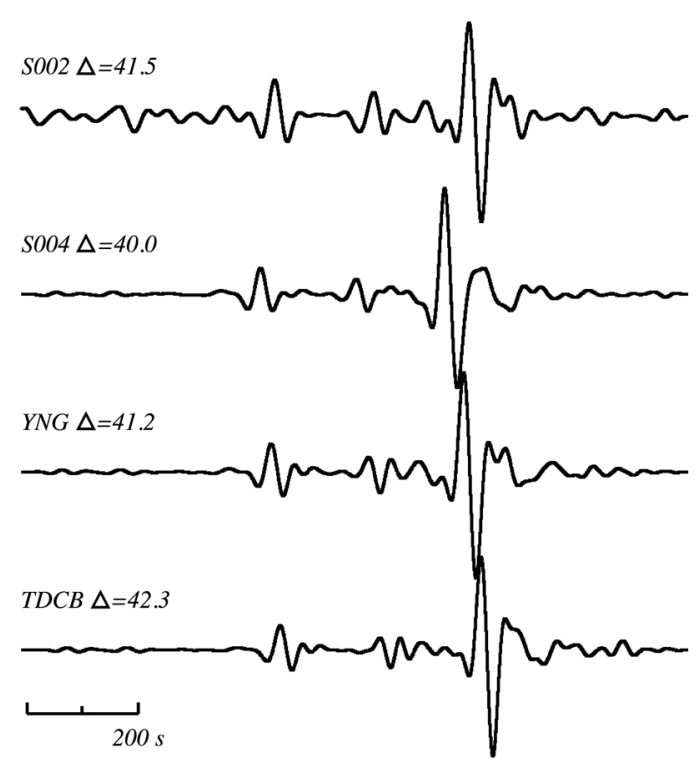

Fig. 9. The same as Fig. 7 but for the New Britain event illustrated in Fig. 6b. Despite a moderate $\mathrm{M}_{\mathrm{w}}$ and longer distances, Rayleigh waves were recorded clearly at all four stations because of the favorable source radiation.

a clear $P$ recording and the magnitude and distance of the event at different frequency bands.

A clear recording of $P$ wave is defined below. For a given frequency range, a routine locates the peak of the envelope of the $30 \mathrm{~s}$ long waveform centered at the isap91 $P$ arrival time (Kennett and Engdahl 1991). This "centroid" time is a better indicator for the arrival of the $P$ wave energy. Then the root-mean-square (rms) amplitude of the " $P$ waveform" in a $20 \mathrm{~s}$ window centered at the centroid time is calculated. The rms amplitude of "noise" is calculated in the window between 20 and $40 \mathrm{~s}$ before the centroid time of $P$. The signal-to-noise ratio (SNR) is estimated as the ratio between the two rms amplitudes. The centroid time sometimes deviates from the iasp91 time by greater than $15 \mathrm{~s}$, but almost without exception these are the cases in which the $P$ wave is overwhelmed by noise and the SNR approaches unity. In this study, a clear $P$ arrival is defined by $\mathrm{SNR} \geq 5$. Webb (1998) used an rms SNR of 6 to define the detection limit, and Sutherland et al. (2004) used an SNR of 2 in their theoretical model.

The SNR is a function of frequency. We start with a 3-pole bandpass butterworth filter between 0.05 and $0.1 \mathrm{~Hz}$, and increase the upper corner to $0.2,0.3,0.5$, and $1 \mathrm{~Hz}$. One $\mathrm{Hz}$ is probably the limit at which the teleseismic waveforms remain mostly coherent across an array. The higher the frequencies, the higher resolution the $P$ waveforms can offer, but more susceptible the phase is to the high noise around the microseism peaks and the attenuation in the mantle. Waveform modeling with land array data low-passed at $0.3 \mathrm{~Hz}$ proves effective in sharpening images of regional heterogeneities initially determined from traveltime tomography (Song and Helmberger 2007). A ray-based traveltime tomography may require a detection at $1 \mathrm{~Hz}$ or higher.

In this test, we examine events of all depths in order to span a long distance range from 30 to $180^{\circ}$ (Fig. 10). If only deeper events, e.g., greater than $100 \mathrm{~km}$, are used to reduce upper mantle attenuation and complications from $p P$ and $s P$, the data are limited to distances less than $80^{\circ}$, the upper limit corresponding to the Fiji-Tonga subduction zone. The examples in Fig. 11 compare the SNR between TDCB and S004. At TDCB the SNR reaches 9.5 for $0.3 \mathrm{~Hz}$. At S004, it remains as high as 8.8 at $0.2 \mathrm{~Hz}$ but drops dramatically to 1.6 at $0.3 \mathrm{~Hz}$. With increasing frequencies anelastic attenuation becomes more and more important and the $P$ phase can be completely clouded by the microseisms in a marine environment. As a result, the SNR of $P$ approaches one. Figure 12 shows a global survey of $P$ wave detection as a function of event magnitude and epicentral distance $(\Delta)$ at S004 and S005 with a threshold at SNR $=5$. Beyond about $100^{\circ}$, the first arrivals are $P_{\text {diff }}$ and $P K P$. The moment magnitude $M_{w}$, rather than $m_{b}$ or $M_{s}$, is used in this analysis. 
Detection of a signal is affected by many factors besides magnitude and distance, e.g., attenuation heterogeneity of the upper mantle, defocusing by the presence of slab, the radiation pattern of the source, and the near-receiver crustal and upper mantle structures. Moreover, the available earthquake sources vary with respect to different OBS experiments. Establishing a quantitative description of the detection limit as a function of magnitude and distance is therefore not attempted here. Blackman et al. (1995) have compiled results from experiments at east-Pacific rise and mid-Atlantic ridge and suggested a detection threshold as a linear relationship $\mathrm{m}=5.3+0.006 \times \Delta$, where $\mathrm{m}$ is the larger of $\mathrm{m}_{\mathrm{b}}$ or $\mathrm{M}_{\mathrm{s}}$. Note that the criterion for "detection" was not specified by Blackman et al. (1995), and an exact comparison with the current study is not the aim here. It is not surprising that the general pattern of the two studies agree, i.e., high SNR detection still occurs at long distances although in much smaller number for $P K P$ than for $P$. Our study shows increasing difficulty of detection with frequency. The numbers of SNR $>5 P$ arrivals drop to less than 10 a year for an upper corner at $0.3 \mathrm{~Hz}$. For the upper corners 0.5 and $1 \mathrm{~Hz}$, the detection reduces to 5 events per year, and they all occurred at $\Delta<90^{\circ}$.

Because of its shorter operation interval, the detection of S002 was analyzed but is not shown. The superposition of the two OT sites, S002 and S005, however, does not exhibit any systematic difference in the detection pattern from S004 in the Huatung basin.

\section{DISCUSSION}

The increase in noise level at $\mathrm{S} 004$ in 2007 relative to 2006, notably in January and March, is unknown in origin. In these two months, no typhoons were reported to have transited the eastern Huatung basin (west of $123^{\circ} \mathrm{E}$ ). The first typhoon formation during 2007 in the western Pacific was announced on 31 March 2007, but the entire path of this typhoon remained east of $140^{\circ} \mathrm{E}$, posing no influence in the Huatung basin. We found enhanced noise levels in the same time intervals on the horizontal components. One possibility is that the sensor was seriously off level, which allowed noise to affect both components. However, the spur seems to be restricted at long periods ( $>20 \mathrm{~s}$ ) and the "leaking" of this noise to higher frequencies, as would occur if the sensor was off-balanced, is not evident. There must be a long-period environmental disturbance to drive the spur, but additional constraints are rare in this region and we cannot identify what is responsible. The location of S004 is far from the weather buoys of the Taiwan Central Weather Bureau installed near the east coast of Taiwan, and not surprisingly the correlations between the wave height recorded there and the noise level at S004 are weak (e.g., Liang et al. 2008). The local wind field can be constructed from satellite data (e.g., Wentz 1997), but it dominates short periods. The possible influences of land slides are low as the local seafloor topography is smooth. At present, this remains an open question and will be revisited in the future.

The horizontal-component recordings in our experiments are not particularly useful for teleseismic studies. In the MELT experiment at the East Pacific Rise, shear-wave splitting and receiver functions were analyzed with horizontal data low-passed to roughly $0.1 \mathrm{~Hz}$ for several large events $\left(M_{\mathrm{s}}>6.6\right)$ (Shen et al. 1998; Wolfe and Solomon 1998). In the recent Hawaiian PLUME project, horizontal component waveforms in the band $0.05-0.1 \mathrm{~Hz}$ can afford shear-wave splitting measurements from $10 \mathrm{~m}_{\mathrm{b}}>6$ events (Collins et al. 2008). The horizontal component noise levels

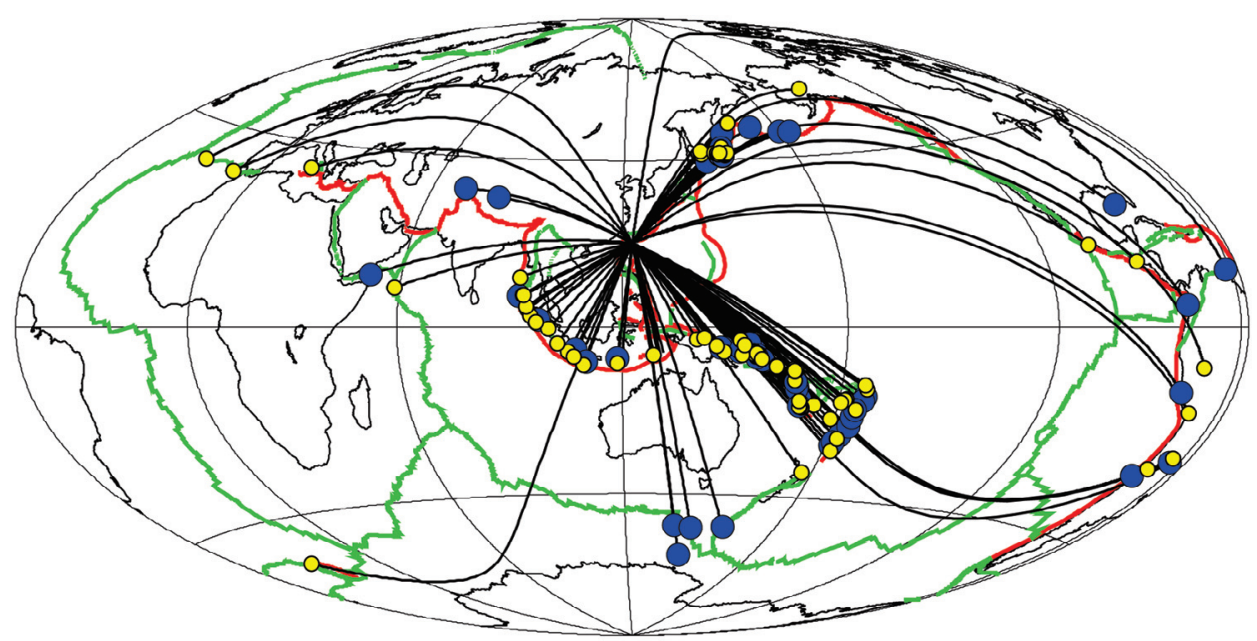

Fig. 10. Events recorded by S004 that were analyzed for $P$ phase threshold. Events for S005 deployed one year later than S004 are not shown, but were located in similar source regions. Blue, larger circles denote SNR $>5$ and yellow, smaller circles denote SNR $<5$ events. Red lines denote trench plate boundary and green lines denote mid-ocean ridges and transform faults. 
2007.119.12.41 Aleutian $117 \mathrm{~km} m_{b}=6.2 M_{w}=6.2$

$$
\Delta=52.21(T D C B), 52.73(\text { SOO4) }
$$
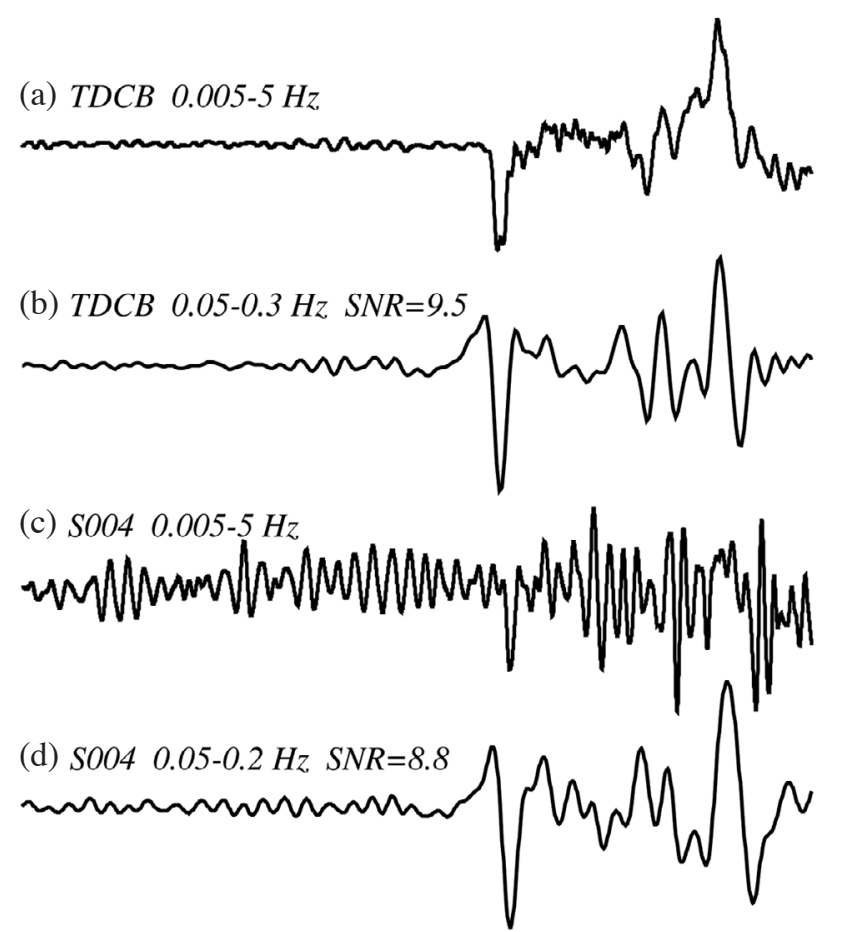

(e) $S 004 \quad 0.05-0.3 \mathrm{~Hz} \quad S N R=1.6$

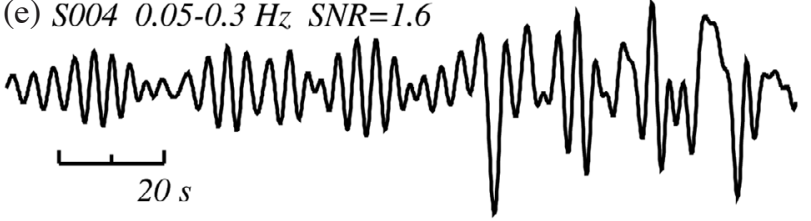

Fig. 11. Example of $P$ phases recorded by TDCB [(a) and (b)] and S004 [(c) - (e)] from an Aleutian event. Station name and frequency range are alongside the traces. (a) and (c) represent nearly original waveforms, and SNR's are shown for filtered waveforms in (b), (d), and (e). The TDCB waveform has high SNR at frequencies $0.3 \mathrm{~Hz}$ and greater while the S004 affords a high SNR only equal to and less than $0.2 \mathrm{~Hz}$. The $P$ waveform is attenuated relative to the microseism at 0.3 $\mathrm{Hz}$ or higher, leading to a reduced SNR.

in our experiments, however, seem to be higher than in the above experiments, and most of the teleseismic shear waves were not prominent enough in this band. The shear-wave splitting studies for the mantle wedge beneath the Mariana and the Lau basin employ primarily subduction zone events that provided large enough shear waves to overcome the noises on the horizontal records (Smith et al. 2001; Pozgay et al. 2007). We have observed some $S$ waveforms at S002 and S005 for events in the subducting Philippine Sea plate under the Ryukyu trench and which will be analyzed in future studies.

Collins et al. (2001) and Stephen et al. (2003), with a series of experiments offshore Hawaii, demonstrated that burial of the sensor in the sediment reduces the noise at frequencies lower than that for the microseisms on the hori-
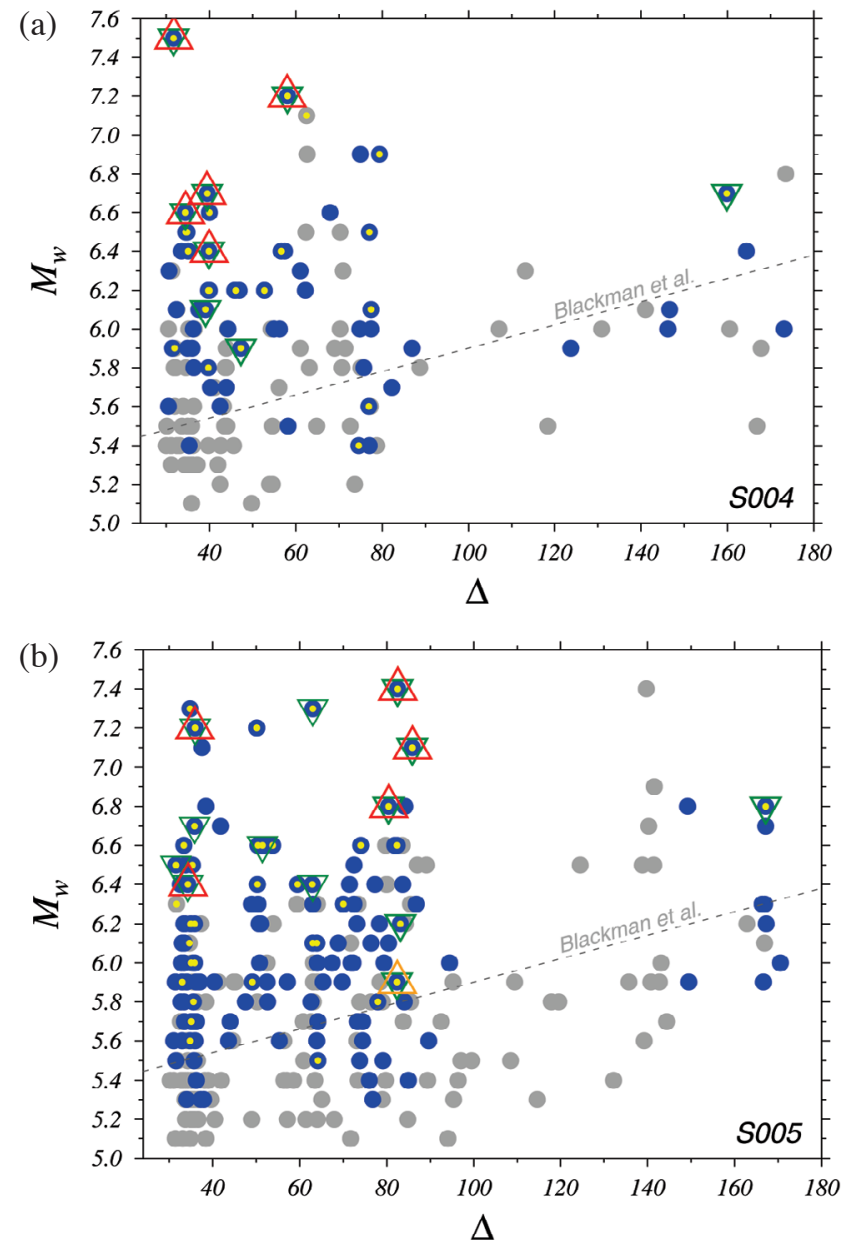

Fig. 12. Events plotted on the $\mathrm{M}_{\mathrm{w}}-\Delta$ space indicating whether $P$ waves were recorded with high SNR, for S004 (a) and S005 (b). Shaded and blue circles denote $\mathrm{SNR}<5$ and $>5$ for $0.05-0.1 \mathrm{~Hz}$, respectively. Blue circles with yellow dots denote SNR $>5$ for $0.05-0.2 \mathrm{~Hz}$. Green inverse triangles denote SNR $>5$ for $0.05-0.3 \mathrm{~Hz}$. Red triangles in (a) denote SNR $>5$ for upper corners of both 0.5 and $1 \mathrm{~Hz}$, and in (b), orange and red triangles for SNR > 5 for 0.5 and $1 \mathrm{~Hz}$, respectively. Shown for reference is the detection threshold proposed by Blackman et al. (1995).

zontals as efficiently as a borehole sensor in the basement. Borehole installation is, on the other hand, necessary to lower the noise levels at the double-frequency microseisms and those due to shear resonance in the low-rigidity sediment at even higher frequencies. Stephen et al. (2003) showed examples of recording clear $P$ arrivals at $2-5 \mathrm{~Hz}$ using a borehole sensor from teleseismic distances. This frequency band is much higher than the $0.1-1 \mathrm{~Hz}$ tested for our data. However, at the same time Stephen et al. (2003) reported troubling installation noise at low frequencies in the borehole experiment. Shinohara et al. (2006) also documented possible installation problems that introduced low frequency noises on the vertical component in one borehole station and on the horizontal component in the other borehole station in the western Pacific. 
What are the lessons this community should learn from this study and previous research? While surface deployment of OBS in this region could accomplish certain research goals (e.g., Kuo et al. 2009) and record clear $P$ arrivals at up to $1 \mathrm{~Hz}$, the noisy horizontal components limit the instrument's capacity to support a full range of seismological research. On the other hand, borehole installation involves high costs and runs the risk of enhanced low frequency noises due to engineering difficulties (Stephen et al. 2003; Shinohara et al. 2006). In contrast, shallow burial of sensor utilizes relatively mature marine technology and is costefficient with respect to what it can achieve (e.g., Collins et al. 2001; Duennebier 2007). Although borehole installation may be the long-term solution for the next generation of ocean-bottom observatories, shallow-burial installation of OBSs should be considered in the design blueprint of new instrumentation and undertaken in all future deployments in Taiwanese waters.

\section{CONCLUSION}

Data from recent broadband OBS campaigns reveal for the first time the noise characteristics on the seafloor in the vicinity of Taiwan and help establish better development of ocean-bottom observatory technology and policy. Deployment of sensors on the surface of the seafloor largely hobbles the usefulness of the horizontal component record. However, this approach allows high quality Rayleigh wave recording in the Huatung basin where the great depth of seafloor has escaped the infragravity waves, in contrast to the degraded quality in the much shallower Okinawa trough. In the frequency band $0.03-0.2 \mathrm{~Hz}$, the vertical-component noise levels match that of typically quiet land stations. The OBSs can be even quieter than some of the stations near the coast of Taiwan. Rayleigh wave recording is promising for $M_{\mathrm{w}} 6.2$ events if focal mechanism is favorable. Numerous $P$ phases have been received with high SNR during the experiments, and with favorable source mechanisms, $P_{\text {diff }}$ and $P K P$ waveforms from events $\mathrm{M}_{\mathrm{w}}>6.4$ can be recorded with fidelity at frequencies as high as $0.3 \mathrm{~Hz}$. Five $P$ phases can be detected each year at $1 \mathrm{~Hz}$ from closer events. However, to fully utilize the three component data and to increase the detection limit for better waveform and earthquake monitoring studies, shallow burial of seismometers in the sediment is cost-efficient and should be recommended for OBS installations in this region.

Acknowledgements We thank the assistance from the Taiwan Ocean Research Institute OBS team and Emmy Chang of Institute of Oceanography, National Taiwan University. Three anonymous reviewers were appreciated for their constructive comments. This study is supported by National Science Council of Taiwan, Republic of China, under grant NSC98-2119-M-001-029.

\section{REFERENCES}

Araki, E., M. Shinohara, S. Sacks, A. Linde, T. Kanazawa, H. Shiobara, H. Mikada, and K. Suyehiro, 2004: Improvement of seismic observation in the ocean by use of seafloor boreholes. Bull. Seismol. Soc. Am., 94, 678690, doi: 10.1785/0120020088. [Link]

Blackman, D. K., J. A. Orcutt, and D. W. Forsyth, 1995: Recording teleseismic earthquakes using ocean-bottom seismographs at mid-ocean ridges. Bull. Seismol. Soc. Am., 85, 1648-1664.

Collins, J. A., F. L. Vernon, J. A. Orcutt, R. A. Stephen, K. R. Peal, F. B. Wooding, F. N. Spiess, and J. A. Hildebrand, 2001: Broadband seismology in the oceans: Lessons from the ocean seismic network pilot experiment. Geophys. Res. Lett., 28, 49-52, doi: 10.1029/2000GL011638. [Link]

Collins, J. A., F. L. Vernon, J. A. Orcutt, and R. A. Stephen, 2002: Upper mantle structure beneath the Hawaiian swell: Constraints from the ocean seismic network pilot experiment. Geophys. Res. Lett., 29, 1522, doi: 10.1029/2001GL013302. [Link]

Collins, J. A., C. J. Wolfe, G. Laske, S. C. Solomon, R. S. Detrick, J. A. Orcutt, D. A. Bercovici, and E. H. Hauri, 2008: Mantle anisotropy beneath the Hawaiian Islands from measurements of shear-wave splitting: Results from the PLUME ocean-bottom and land seismograph deployments. Eos, Trans., AGU, 89, Fall Meet. Suppl., Abstract \#DI21A-1727.

Dolenc, D., B. Romanowicz, D. Stakes, P. McGill, and D. Neuhauser, 2005: Observations of infragravity waves at the Monterey ocean bottom broadband station (MOBB). Geochem. Geophys. Geosyst., 6, Q09002, doi: 10.1029/2005GC000988. [Link]

Dolenc, D., B. Romanowicz, P. McGill, and W. Wilcock, 2008: Observations of infragravity waves at the oceanbottom broadband seismic stations Endeavour (KEBB) and Explorer (KXBB). Geochem. Geophys. Geosys., 9, Q05007, doi: 10.1029/2008GC001942. [Link]

Duennebier, F. K. and G. H. Sutton, 2007: Why bury ocean bottom seismometers? Geochem. Geophys. Geosyst., 8, Q02010, doi: 10.1029/2006GC001428. [Link]

Kennett, B. L. N. and E. R. Engdahl, 1991: Traveltimes for global earthquake location and phase identification. Geophys. J. Int., 105, 429-465, doi: 10.1111/j.1365246X.1991.tb06724.x. [Link]

Kuo, B. Y., W. C. Chi, C. R. Lin, E. T. Y. Chang, J. Collins, and C. S. Liu, 2009: Two-station measurement of Rayleigh-wave phase velocities for the Huatung basin, the westernmost Philippine Sea, with OBS: Implications for regional tectonics. Geophys. J. Int., 179, 1859-1869, doi: 10.1111/j.1365-246X.2009.043 91.x. [Link]

Liang, W. T., Y. H. Liu, and H. Kao, 2004: Source param- 
eters of regional earthquakes in Taiwan: January-December, 2002. Terr. Atmos. Ocean. Sci., 15, 727-741.

Liang, W. T., C. C. Liu, R. Y. Chen, B. S. Huang, F. T. $\mathrm{Wu}$, and C. Y. Wang, 2008: Ambient noise levels in the Taiwan region. Eos, Trans., AGU, 89, Fall Meet. Suppl., Abstract \#T31C-2024.

MaNamara, D. E. and R. P. Buland, 2004: Ambient noise levels in the continental United States. Bull. Seismol. Soc. Am., 94, 1517-1527, doi: 10.1785/012003001. [Link]

Okada, Y., K. Kasahara, S. Hori, K. Obara, S. Sekiguchi, H. Fujiwara, and A. Yamamoto, 2004: Recent progress of seismic observation networks in Japan - Hi-net, F-net, K-NET and KiK-net. Earth Planets Space, 56, $\mathrm{xV}-\mathrm{xx}$ viii.

Peterson, J., 1993: Observations and modeling of seismic back-ground noise. USGS Open File Report 93-322.

Pozgay, S. H., D. A. Wiens, J. A. Conder, H. Shiobara, and H. Sugioka, 2007: Complex mantle flow in the Mariana subduction system: Evidence from shear wave splitting. Geophys. J. Int., 170, 371-386, doi: 10.1111/j.1365-246X.2007.03433.x. [Link]

Shen, Y., A. F. Sheehan, K. G. Dueker, C. de Groot-Hedlin, and H. Gilbert, 1998: Mantle discontinuity structure beneath the southern east Pacific rise from P-to-S converted phases. Science, 280, 1232-1235, doi: 10.1126/ science.280.5367.1232. [Link]

Shinohara, M., E. Araki, T. Kanazawa, K. Suyehiro, M. Mochizuki, T. Yamada, K. Nakahigashi, Y. Kaiho, and Y. Fukao, 2006: Deep-sea borehole seismological observatories in the western Pacific: Temporal variation of seismic noise level and event detection. Ann. Geophys., 49, 625-641.

Smith, G. P., D. A. Wiens, K. M. Fischer, L. M. Dorman, S. C. Webb, and J. A. Hildebrand, 2001: A complex pattern of mantle flow in the Lau backarc. Science, 292, 713-716, doi: 10.1126/science.1058763. [Link]

Song, T.-R. A. and D. V. Helmberger, 2007: P and S wave- form modeling of continental sub-lithospheric detachment at the eastern edge of the Rio Grande rift. $J$. Geophys. Res., 112, B07319, doi: 10.1029/2007JB00 4942. [Link]

Stephen, R. A., F. N. Spies, J. A. Collins, J. A. Hildebrand, J. A. Orcutt, K. R. Peal, F. L. Verson, and F. B. Wooding, 2003: Ocean seismic network pilot experiment. Geochem. Geophys. Geosys., 4, 1092, doi: 10.1029/2002GC000485. [Link]

Sutherland, F. H., F. L. Vernon, J. A. Orcutt, J. A. Collins, and R. A. Stephen, 2004: Results from OSNPE: Improved teleseismic earthquake detection at the seafloor. Bull. Seismol. Soc. Am., 94, 1868-1878, doi: 10.1785/012003088. [Link]

Toomey, D. R., W. S. D. Wilcock, S. C. Solomon, W. C. Hammond, and J. A. Orcutt, 1998: Mantle seismic structure beneath the MELT region of the east Pacific rise from $\mathrm{P}$ and $\mathrm{S}$ wave tomography. Science, 280, 1224-1227, doi: 10.1126/science.280.5367.1224. [Link]

Webb, S. C., 1998: Broadband seismology and noise under the ocean. Rev. Geophys., 36, 105-142.

Webb, S. C., 2002: Seismic noise on land and on the sea floor, Int. Handbook of Earthquake and Engineering Seismology. 81A.

Webb, S. C. and W. C. Crawford, 1999: Long-period seafloor seismology and deformation under ocean waves. Bull. Seismol. Soc. Am., 89, 1535-1542.

Webb, S. C., X. Zhang, and W. Crawford, 1991: Infragravity waves in the deep ocean. J. Geophys. Res., 96, 2723-2736.

Wentz, F. J., 1997: A well-calibrated ocean algorithm for special sensor microwave/imager. J. Geophys. Res., 102, 8703-8718.

Wolfe, C. J. and S. C. Solomon, 1998: Shear-wave splitting and implications for mantle flow beneath the MELT region of the east Pacific rise. Science, 280, 1230-1232, doi: 10.1126/science.280.5367.1230. [Link] 